\title{
Análise de crescimento e partição de assimilados em plantas de fisalis submetidas a intervalos de adubação foliar
}

\section{Growth analisys and assimilate partitioning in physalis plants under leaf fertilization intervals}

\author{
Tiago Pedó ${ }^{1 *}$; Tiago Zanatta Aumonde ${ }^{1,2}$; Nei Fernandes Lopes ${ }^{3}$; \\ Francisco Amaral Villela ${ }^{4}$; Carlos Rogério Mauch ${ }^{5}$
}

\section{Resumo}

O trabalho foi conduzido em casa de vegetação e objetivou analisar o crescimento e a partição de assimilados em Physalis peruviana submetida a intervalos de adubação foliar. As plantas foram coletadas a intervalos regulares de quatorze dias após o transplante até o final do ciclo e foram determinados a massa seca e a área foliar. A partir dos dados primários foi aplicada a análise de crescimento, sendo calculados a massa seca total $\left(\mathrm{W}_{\mathrm{t}}\right)$, taxas de produção de matéria seca $\left(\mathrm{C}_{\mathrm{t}}\right)$, crescimento relativo $\left(\mathrm{R}_{\mathrm{w}}\right)$ e assimilatória liquída $\left(\mathrm{E}_{\mathrm{a}}\right)$, índice de área foliar $(\mathrm{L})$, razões de área foliar $\left(\mathrm{F}_{\mathrm{a}}\right)$ e massa foliar $\left(\mathrm{F}_{\mathrm{w}}\right)$, área foliar específica $\left(\mathrm{S}_{\mathrm{a}}\right)$, partição de matéria seca entre órgãos e o número de frutos. Plantas de Physalis peruviana submetidas à adubação foliar quinzenal atingiram maior $\mathrm{W}_{\mathrm{t}}, \mathrm{C}_{\mathrm{t}}$, superior número de frutos e semelhante matéria seca de frutos $\left(\mathrm{W}_{\mathrm{fr}}\right)$ a plantas submetidas à aplicação de adubação foliar semanal e superior $\mathrm{W}_{\mathrm{fr}}$ em relação a plantas sem adubação foliar. Desse modo, a aplicação de adubação foliar proporcionou benefícios no crescimento e na partição de assimilados em plantas de Physalis peruviana. Palavras-chave: Physalis peruviana, área foliar, matéria seca, taxas de crescimento

\begin{abstract}
The work was conducted in greenhouse and aimed to analyze the growth and partitioning of assimilates in Physalis peruviana subjected in intervals of leaf fertilization. The plants were collected at regular intervals of fourteen days after transplantation until the end of the cycle and determined the dry mass and leaf area. From the primary data analysis was applied to growth analysis and calculated the total dry matter production $\left(\mathrm{W}_{\mathrm{t}}\right)$, rates of dry matter production $\left(\mathrm{C}_{\mathrm{t}}\right)$, relative growth $\left(\mathrm{R}_{\mathrm{w}}\right)$, net assimilation $\left(\mathrm{E}_{\mathrm{a}}\right)$, leaf area index $(\mathrm{L})$, relative growth of leaf area $\left(\mathrm{F}_{\mathrm{a}}\right)$ and ratios of leaf area and leaf mass $\left(\mathrm{F}_{\mathrm{w}}\right)$, specific leaf area $\left(\mathrm{S}_{\mathrm{a}}\right)$ and dry matter partitioning between organs. Plants of Physalis peruviana subjected to leaf fertilization biweekly reached higher $\mathrm{W}_{\mathrm{t}}, \mathrm{C}_{\mathrm{t}}$, number of fruits and similar dry mass of fruits $\left(\mathrm{W}_{\mathrm{fr}}\right)$ of plants subjected to foliar weekly application and higher $\mathrm{W}_{\mathrm{fr}}$ compared to plants without application leaf of fertilization. Thus, the application of leaf fertilization provided benefits of growth and the partition of assimilates in Physalis peruviana plants.
\end{abstract}

Key words: Physalis peruviana, leaf area, dry matter, growth rate

\footnotetext{
${ }^{1} \mathrm{Eng}^{{ }^{\circ \mathrm{s}}} \mathrm{Agr}^{\mathrm{os}_{\mathrm{s}}}$, Discente de Doutorado em PPG C\&T de Sementes, Dept ${ }^{\circ}$ de Fitotecnia, FAEM, Universidade Federal de Pelotas, UFPel, Pelotas, RS. Bolsista CAPES. E-mail: tiago.pedo@gmail.com; tiago.aumonde@gmail.com

2 Prof. Dr. Faculdade de Agronomia Eliseu Maciel, Departamento de Fitotecnia, PPG em Ciência e Tecnologia de Sementes, Universidade Federal de Pelotas. E-mail: tiago.aumonde@gmail.com

${ }^{3}$ Eng $^{\mathrm{o}}$ Agr $^{\circ}$, Prof. Titular Aposentado, Dept ${ }^{\circ}$ de Botânica, PPG Fisiologia Vegetal, UFPel, Pelotas, RS. E-mail: neilopes@ufpel. edu.br

${ }^{4}$ Eng $^{\circ}$ Agrícola, Prof. Associado, Dept ${ }^{\circ}$ de Fitotecnia, PPG C\&T de Sementes, UFPel, Pelotas, RS. Bolsista Produtividade em Pesquisa Nível II do CNPq. E-mail: francisco.villela@ufpel.edu.br

${ }^{5}$ Eng $^{\circ}$ Agr ${ }^{\circ}$, Prof. Associado, Dept ${ }^{\circ}$ de Fitotecnia, PPG Sistemas de Produção Agrícola Familiar, UFPel, Pelotas, RS. E-mail: crmauch@gmail.com

* Autor para correspondência
} 
A espécie Physalis peruviana, conhecida como fisalis, pertencente a família Solanaceae é originária das regiões Amazônica e Andina (THOMÉ; OSAKI, 2010). Devido à propriedade nutracêutica de seus frutos, proprcionada pela elevada atividade antioxidante, vitaminas A, C e E e altos níveis de Fe e $\mathrm{P}$, vem se destacando no cenário nacional como nicho de mercado (WU et al., 2005; ARANGO; RODRÍGUEZ; CAMPUZANO, 2010; SEVERO et al., 2010).

As plantas, de maneira geral, apresentam melhor crescimento e desenvolvimento sob condições adequadas de fertilidade do solo, portanto, o fornecimento de doses adequadas de nutrientes via adubações de plantio, cobertura e/ou foliar é essencial para que as plantas expressem o seu máximo potencial produtivo. A adubação foliar, em específico, tem sido bastante empregada em diversas espécies, como forma de suprir micronutrientes, por agregar vantagens, tais como: baixo custo de aplicação e aumento de produtividade e de massa de sementes (BEVILAQUA; SILVA FILHO; POSSENTI, 2002; RODRIGUES et al., 2002). Entretanto, devido ao cultivo recente no Brasil, a espécie Physalis peruviana carece de informações fitotécnicas de manejo, comportamento vegetativo e respostas fisiológicas a diferentes condições de fertilidade do solo e intervalos de adubação foliar.

A análise de crescimento, método acessível e preciso, permite inferir os processos morfofisiológicos das plantas, consistindo no primeiro passo para a interpretação e a análise de produção primária. Sendo assim, é uma ferramenta importante no estudo da adaptação das plantas sob diferentes condições ambientais e de manejo (AUMONDE et al., 2011).

Devido ao elevado valor de comercialização e ao mercado promissor dos frutos de Physalis peruviana, existe a necessidade de maior conhecimento sobre esta espécie. Dessa forma, a análise de crescimento, por permitir o conhecimento de características fisiológicas de crescimento e de partição de assimilados ao longo do desenvolvimento das plantas, proporciona a descrição do comportamento vegetativo, da resposta da espécie a adubação foliar e permite inferir de maneira consistente sobre o manejo da cultura.

A partir do exposto, este trabalho objetivou analisar comparativamente o crescimento e a partição de assimilados em plantas de Physalis peruviana submetidas a diferentes intervalos de adubação foliar.

O experimento foi realizado em casa de vegetação, do tipo arco pampeana, na Universidade Federal de Pelotas, situada a altitude de 13 m, 31 52' de latitude Sul e 52 21' de longitude Oeste. O clima dessa região, segundo a classificação de Köppen, é do tipo Cfa, com chuvas bem distribuídas e verão quente; e o solo da área experimental foi classificado como sendo planossolo.

O delineamento experimental foi inteiramente casualisado, com três tratamentos (sem adubação, adubação semanal e quinzenal) e quatro repetições. Cada parcela constou de 140 plantas, sendo que, em cada coleta foi retirada uma planta por parcela, totalizando 11 coletas.

A semeadura foi realizada em 27/12/2010, em bandejas de poliestireno expandido de 128 células, contendo substrato comercial H. Decker ${ }^{\circledR}$, sendo a irrigação das mudas efetuada pelo sistema flutuante e a água reposta de acordo com a demanda hídrica, procurando manter a lâmina de água uniforme com $50 \mathrm{~mm}$ de altura. As mudas foram transplantadas em 07/02/2011, quando apresentavam quatro folhas definitivas. O transplante foi realizado em canteiros de 5,0 $\mathrm{m}$ de comprimento e $1,20 \mathrm{~m}$ de largura, utilizando o espaçamento de 0,25 x 0,80 $\mathrm{m}$ e cobertura de polietileno preto, objetivando o controle de plantas daninhas e evitar o escorrimento da calda aplicada nas plantas para o solo.

A adubação do solo foi efetuada previamente de acordo com análise do solo e com base no Manual de Adubação e Calagem para os Estados do RS e $\mathrm{SC}$, conforme o recomendado para a cultura do 
tomateiro para a estimativa de produção de $20 \mathrm{tha}^{-1}$. Conduzido sem poda por meio de fitilhos polietileno e a irrigação efetuada pelo sistema de irrigação por gotejamento, efetuada quando necessário, para manter a umidade do solo na capacidade de campo.

A adubação foliar teve início quando as plantas atingiram o estádio de quinze folhas, sendo empregado o fertilizante foliar Torped ${ }^{\circledR}$ composto por macro e micronutrientes na proporção de 1 $\mathrm{mL} \mathrm{L}{ }^{-1}$, conforme indicado pelo fabricante para o tomateiro. O volume de calda empregado foi de $0,5 \mathrm{~L} \mathrm{~m}^{-2}$, sendo a aplicação efetuada de maneira uniforme sobre as plantas por meio de pulverizador costal submetido à tríplice lavagem após cada aplicação.

Para as avaliações, foram efetuadas onze coletas sucessivas, em intervalos regulares de quatorze dias após o transplante, durante todo o ciclo da cultura. Em cada coleta, as plantas foram cortadas rentes ao solo e separadas em raiz, folhas, caule e frutos. Em seguida determinou-se a área foliar $\left(\mathrm{A}_{\mathrm{f}}\right)$, e os órgãos foram acondicionados em envelopes de papel pardo separadamente e submetidos à secagem, em estufa de ventilação forçada, a temperatura de $70 \pm 2{ }^{\circ} \mathrm{C}$, onde as plantas de cada coleta permaneceram até massa constante, por $72 \mathrm{~h}$.

$\mathrm{A}$ área foliar $\left(\mathrm{A}_{\mathrm{f}}\right)$ foi determinada com medidor de área Licor modelo LI-3100 e o índice de área foliar (L) calculado pela fórmula:

$$
L=A_{f} / S_{t}
$$

sendo $\mathrm{S}_{\mathrm{t}}$ a área superficial do canteiro ocupada pela planta. Os dados primários de matéria seca total acumulada $\left(\mathrm{W}_{\mathrm{t}}\right)$ foram ajustados pela equação logística simples:

$$
W_{\mathrm{t}}=\mathrm{W}_{\mathrm{m}} /\left(\mathbf{1}+\mathrm{Ae}^{-\mathrm{Bt}}\right),
$$

sendo $\mathrm{W}_{\mathrm{m}}$ a estimativa assintótica do crescimento máximo, "A" e "B" constantes de ajustamento, "e" a base natural de logaritmo neperiano e "t" o tempo em dias após o transplante (RICHARDS, 1969). Enquanto, os dados primários de área foliar $\left(\mathrm{A}_{\mathrm{f}}\right)$, de matéria seca da folha, caule e fruto, número de frutos por metro quadrado foram submetidos à análise de variância e quando significativo a 5\%, ajustados por polinômios ortogonais. Os valores instantâneos da taxa de produção de matéria seca total $\left(\mathrm{C}_{\mathrm{t}}\right)$, de folha $\left(\mathrm{C}_{\mathrm{f}}\right)$, caule $\left(\mathrm{C}_{\mathrm{c}}\right)$ e fruto $\left(\mathrm{C}_{\mathrm{fr}}\right)$ foram obtidos por meio de derivadas temporais das equações ajustadas da matéria seca total $\left(\mathrm{W}_{\mathrm{t}}\right)$, de folha $\left(\mathrm{W}_{\mathrm{f}}\right)$, caule $\left(\mathrm{W}_{\mathrm{c}}\right)$ e fruto $\left(\mathrm{W}_{\mathrm{fr}}\right)$, respectivamente (RADFORD, 1967). Para determinação dos valores instantâneos da taxa de crescimento relativo $\left(\mathrm{R}_{\mathrm{w}}\right)$ e taxa de crescimento relativo de área foliar $\left(\mathrm{R}_{\mathrm{a}}\right)$ foram empregadas, respectivamente, as fórmulas:

$$
R_{w}=1 / W_{t} \cdot d_{w} / d_{t} e R_{a}=1 / A_{f} \cdot d A_{f} / d_{t} .
$$

Os valores instantâneos da taxa assimilatória líquida $\left(\mathrm{E}_{\mathrm{a}}\right)$, razão de área foliar $\left(\mathrm{F}_{\mathrm{a}}\right)$, razão de massa foliar $\left(\mathrm{F}_{\mathrm{w}}\right)$ e área foliar específica $\left(\mathrm{S}_{\mathrm{a}}\right)$ foram estimadas, respectivamente, por meio das equações:

$$
\begin{gathered}
E_{a}=1 / A_{f} \cdot d_{w} / d_{t} \\
F_{a}={ }^{A_{f}} / W_{t} \\
F_{w}=W_{f} / W_{t} \\
S_{a}={ }_{f} / W_{f}(R A D F O R D, 1967) .
\end{gathered}
$$

Os dados foram assim analisados pelo fato da análise de crescimento ser baseada na logística simples e não atender as pressuposições básicas da análise de variância, sendo modelo não aditivo e não linear. Além disso, nesta categoria de análise logística, os erros são correlacionados ao longo do tempo e assim não independentes (DIAS; BARROS, 2009; AUMONDE et al., 2011). Neste sentido, por constituir-se em dados quantitativos, uma maneira 
adequada de tratar os dados de crescimento ao longo do desenvolvimento vegetal verifica-se por meio de tendência das curvas de crescimento (RADFORFD, 1967; BARREIRO et al., 2006).

De acordo com a Figura 1, verifica-se que a matéria seca total $\left(\mathrm{W}_{\mathrm{t}}\right)$ das plantas de fisalis, nos três intervalos de aplicação de adubação foliar, seguiu tendência logística, com elevado coeficiente de determinação $\left(R^{2} \geq 0,98\right)$, sendo as diferenças incrementadas na produção de matéria seca entre os intervalos de aplicação ao longo do desenvolvimento das plantas (Figura 1a). Indiferentemente ao intervalo de aplicação, houve crescimento inicial lento até os 42 dias após o transplante (DAT), o que é frequente nesta fase e pode ser explicada pela baixa absorção de água e de nutrientes, diminuta área foliar, reduzidas taxas de respiração e taxa assimilatória líquida (AUMONDE et al., 2011). Entretanto, dos 42 DAT aos 126 DAT ocorreu período de rápido crescimento, sendo que as plantas submetidas à aplicação quinzenal atingiram o máximo de $822,69 \mathrm{~g} \mathrm{~m}^{-2}$ e àquelas sob adubação semanal alcançaram $628,71 \mathrm{~g} \mathrm{~m}^{-2}$ e foram similares às plantas sem adubação com o máximo de 609,06 $\mathrm{g} \mathrm{m}^{-2}$ (Figura 1a).

As taxas de produção de matéria seca $\left(\mathrm{C}_{t}\right)$ foram reduzidas inicialmente e corroboraram com o lento crescimento inicial (Figura 1b). Indiferentemente ao intervalo de aplicação, houve a partir dos 42 DAT período de elevada taxa de produção de matéria seca que atingiu o máximo aos 84 DAT, sendo que as plantas submetidas à adubação quinzenal foram superiores $(15,49 \mathrm{~g}$ $\left.\mathrm{m}^{-2} \mathrm{~d}^{-1}\right)$ às plantas submetidas à adubação semanal $\left(11,86 \mathrm{~g} \mathrm{~m}^{-2} \mathrm{~d}^{-1}\right)$ e sem adubação $\left(11,76 \mathrm{~g} \mathrm{~m}^{-2} \mathrm{~d}^{-1}\right)$ que foram similares entre si. $\mathrm{O}$ aumento nas taxas de produção de matéria seca, especialmente em plantas submetidas à adubação quinzenal pode ser atribuído até certo ponto, ao aumento da área foliar e do montante de fotoassimilados produzidos e destinados ao crescimento e ao desenvolvimento vegetal (LOPES; MAESTRI, 1973). Desse modo, é possível inferir que o aumento no intervalo de adubação não proporcionou alteração temporal em $\mathrm{C}_{\mathrm{t}}$, entretanto sob intervalo quinzenal, a adubação foliar beneficiou quantitativamente $\mathrm{C}_{\mathrm{t}}$ das plantas de fisalis.

As taxas de crescimento relativo $\left(\mathrm{R}_{\mathrm{w}}\right)$ foram máximas aos 14 DAT (Figura 1c), período em que a maior parte das folhas são jovens e possuem elevada capacidade fotossintética, favorecendo maior incremento de matéria seca em relação a matéria seca pré-existente na fase inicial de crescimento. A partir dos 14 DAT houve decréscimo sistemático de $\mathrm{R}_{\mathrm{w}}$ até o final do desenvolvimento das plantas. Essa tendência em parte está relacionada ao aumento gradativo de tecidos não fotossintetizantes e à elevação da atividade respiratória (LOPES; MAESTRI, 1973). Cabe salientar que, as taxas de crescimento relativo foram similares em todos os intervalos de aplicação, assim, plantas submetidas à adubação foliar não obtiveram maior incremento de matéria seca em relação àquela pré-existente, comparativamente às plantas sem adubação foliar.

A taxa assimilatória líquida $\left(\mathrm{E}_{\mathrm{a}}\right)$ apresentou um primeiro pico aos $28 \mathrm{DAT}$ quando houve maior $\mathrm{E}_{\mathrm{a}} \mathrm{em}$ plantas sem adubação foliar $\left(3,51 \mathrm{~g} \mathrm{~m}^{2} \mathrm{dia}^{-1}\right)$ seguida por plantas sob adubação quinzenal $\left(2,80 \mathrm{~g} \mathrm{~m}^{2} \mathrm{dia}^{-}\right.$ 1) e semanal (1,41 $\left.\mathrm{g} \mathrm{m}^{2} \mathrm{dia}^{-1}\right)$ (Figura 1d). O maior tempo necessário para assimilação, conversão e aproveitamento dos nutrientes aplicados em plantas sob adubação foliar reduzem $\mathrm{E}_{\mathrm{a}}$, possivelmente por necessitarem de compostos provenientes do processo fotossintético (MARENCO; LOPES, 2009). Assim o maior $E_{a}$ inicial em plantas sem adubação foliar pode ser relacionado a tais processos. Desse modo, é possível verificar que aos 28 DAT a diferença entre a fotossíntese bruta e a respiração foi superior em plantas sem adubação foliar, que se mostraram mais eficientes na conversão de radiação solar em matéria seca nesta avaliação. Entretanto, houve um segundo pico de $\mathrm{E}_{\mathrm{a}}$ com o inicio da formação dos órgãos reprodutivos aos 70 DAT em plantas sem adubação foliar $\left(1,82 \mathrm{~g} \mathrm{~m}^{2} \mathrm{dia}^{-1}\right)$, que ainda mantiveram superior $\mathrm{E}_{\mathrm{a}}$ em relação a plantas submetidas adubação semanal (2,21 $\left.\mathrm{g} \mathrm{m}^{2} \mathrm{dia}^{-1}\right)$ 
que atingiram o segundo pico de $\mathrm{E}_{\mathrm{a}}$ aos $84 \mathrm{DAT}$, juntamente com plantas sob adubação quinzenal. Nestas, foi evidenciado que $\mathrm{E}_{\mathrm{a}}$ sofreu inversão positiva em comparação a plantas sem adubação e com adubação semanal, o que pode ser relacionado à similar matéria seca e número de frutos de plantas de fisalis com adubação foliar semanal. Desse modo, embora tenha ocorrido atraso temporal de 14 DAT na obtenção da máxima taxa assimilatória líquida em plantas submetidas à adubação foliar, a aplicação quinzenal proporcionou aumento na eficiência da produção líquida de assimilados comparativamente aos demais tratamentos. Aliado a isso, o segundo pico de $\mathrm{E}_{\mathrm{a}}$ pode ser explicado pela pelo aumento da taxa fotossintética das folhas objetivando o fornecimento e o armazenamento de assimilados nos frutos (AUMONDE et al., 2011).

No que concerne ao índice de área foliar (L), foi semelhante em todos os tratamentos e obtido com elevado coeficiente de determinação $\left(\mathrm{R}^{2}=0,99\right)$ (Figura 1e). O L se mostrou lento até os 28 DAT o que contribuiu para as reduzidas taxas assimilatórias líquidas e produção de matéria seca total, no inicio do crescimento. No período de 28 a 116 DAT, o L foi similar e obteve tendência ao acréscimo em plantas submetidas a aplicações semanal e quinzenal. Plantas de fisalis sem adubação foliar apresentaram L superior aos demais tratamentos dos 116 DAT ao final do ciclo, contribuindo para a elevação do auto-sombreamento e indicando que houve maior área superficial de solo ocupada por folhas comparativamente aos demais tratamentos no referido período.
A razão de área foliar $\left(\mathrm{F}_{\mathrm{a}}\right)$ apresentou tendência de aumento acelerado a partir dos 28 DAT (Figura 1f). As curvas de $\mathrm{F}_{\mathrm{a}}$ atingiram o máximo aos $42 \mathrm{DAT}$, sendo plantas submetidas à adubação foliar semanal superiores com $\mathrm{F}_{\mathrm{a}}$ máxima de $0,085 \mathrm{~m}^{2} \mathrm{~g}^{-1}$ seguidas por plantas sob aplicação quinzenal com $0,045 \mathrm{~m}^{2}$ $\mathrm{g}^{-1}$ e sem aplicação com similar $\mathrm{F}_{\mathrm{a}}$ de $0,044 \mathrm{~m}^{2} \mathrm{~g}^{-1}$. Essa forte tendência ao aumento de $\mathrm{F}_{\mathrm{a}}$ no período inicial de crescimento é devida a maior parte dos assimilados provenientes da fotossíntese serem destinados à formação de folhas, com o objetivo de maior captação de radiação solar (URCHEI; RODRIGUES; STONE, 2000). Entretanto, houve a partir dos 42 DAT decréscimo nas curvas de $\mathrm{F}_{\mathrm{a}}$ que se estendeu até o final do desenvolvimento das plantas, que pode ser explicado em parte, pelo aumento gradual de tecidos não assimilatórios e a formação de estruturas reprodutivas que se constituem em dreno forte (LOPES; MAESTRI, 1973). Embora $\mathrm{F}_{\mathrm{a}}$ tenha sido superior em plantas submetidas à adubação semanal, não houve elevação na $\mathrm{E}_{\mathrm{a}}$ neste intervalo de adubação comparativamente aos demais intervalos, o que indica que plantas de fisalis submetidas à adubação foliar semanal, mesmo tendo maior área foliar útil para a fotossíntese foram menos eficientes na produção líquida de assimilados e provavelmente refletiu em menor produção de matéria seca total em comparação as plantas submetidas adubação foliar quinzenal. 
Figura 1. Produção de matéria seca total (a), taxa de produção de matéria seca (b), taxa de crescimento relativo (c), taxa assimilatória liquida (d), índice de área foliar (e), razão de área foliar (f), razão de massa foliar (g) e área foliar específica (h) de plantas de fisalis submetidas a três intervalos de adubação foliar. Sendo: 0 dias $(-), 7$ dias $(\cdots \cdots . .$. ) e 15 dias (.......).

(a)

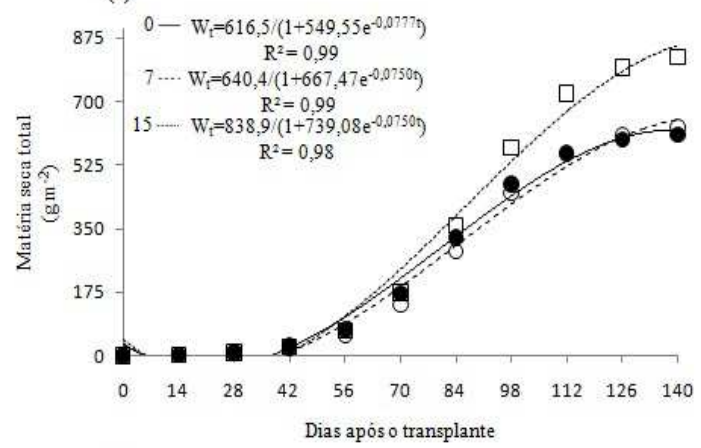

(c)

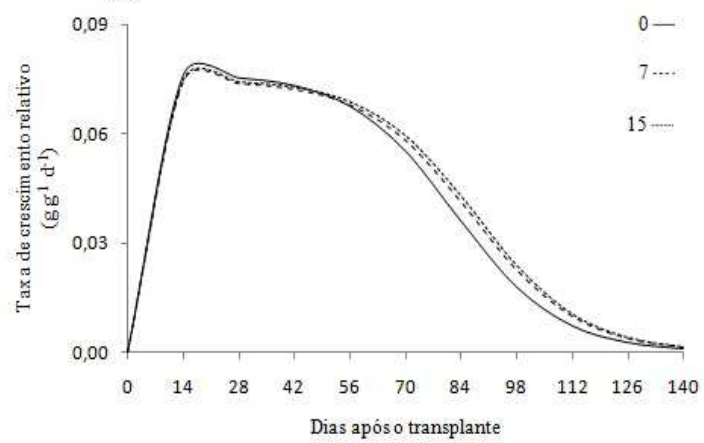

(e)

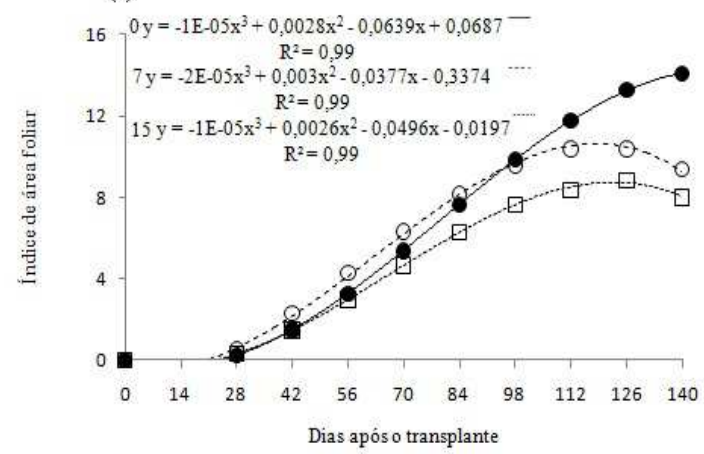

(g)

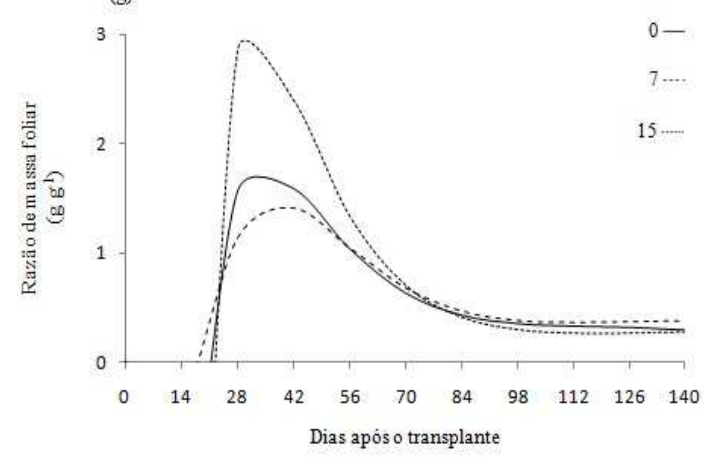

(b)

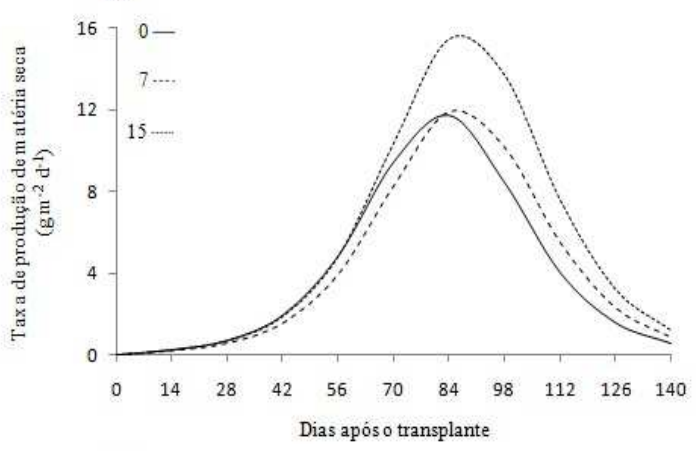

(d)

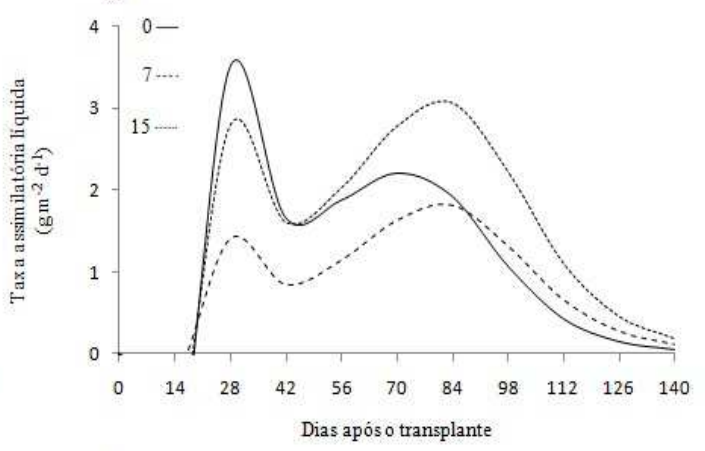

(f)

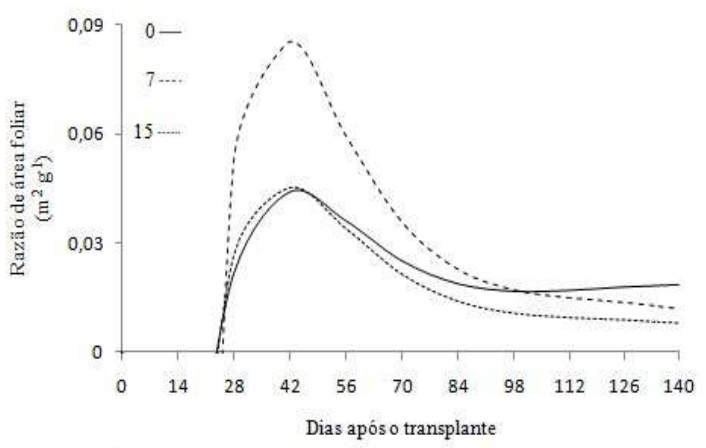

(h)

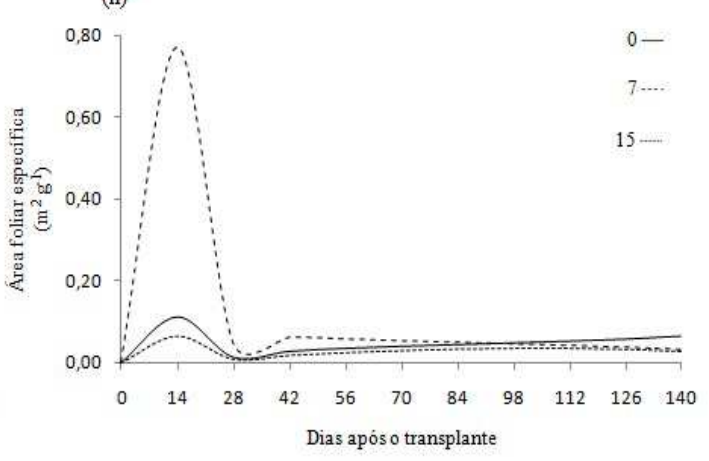

Fonte: Elaboração dos autores. 
Comparativamente, a razão de massa foliar $\left(\mathrm{F}_{\mathrm{w}}\right)$ foi superior e máxima aos 28 DAT em plantas sem adubação foliar e com adubação foliar quinzenal, sendo está última superior às demais. Enquanto, plantas sob adubação semanal retardaram a máximo $\mathrm{F}_{\mathrm{w}}$ em 7 DAT e se mostraram inferiores aos demais intervalos de adubação foliar (Figura 1g). Neste sentido, o $\mathrm{F}_{\mathrm{w}}$ de plantas sob a adubação quinzenal indica que inicialmente as folhas se constituíram em dreno mais forte comparativamente aos demais intervalos de adubação, pois $\mathrm{F}_{\mathrm{w}}$ é uma característica de crescimento demonstra maior investimento de assimilados na formação do aparato fotossintético, mais especificamente nas folhas (AUMONDE et al., 2011), ao passo que, a adubação semanal evidencia possível fitotoxicidez. Assim, a maior $\mathrm{F}_{\mathrm{w}}$ inicial é devida a maior parte da matéria seca ser alocada nas folhas (AUMONDE et al., 2011), órgãos dotados de elevada capacidade mobilizadora de metabólitos no início do crescimento da espécie, exercendo a adubação semanal, influência temporal no comportamento desta variável enquanto a adubação quinzenal alterou quantitativamente $\mathrm{F}_{\mathrm{w}}$. Conforme esperado, houve declínio de $\mathrm{F}_{\mathrm{w}}$ ao decorrer do desenvolvimento de plantas de fisalis, uma vez que, ao longo do crescimento e com a formação dos órgãos reprodutivos, as folhas deixam de ser dreno metabólico preferencial e exportam seus assimilados para estes órgãos (LOPES; MAESTRI, 1973).

Os maiores valores de área foliar específica $\left(\mathrm{S}_{\mathrm{a}}\right)$ foram atingidos aos 14 DAT com posterior decréscimo em todos os intervalos de adubação, sendo maior no intervalo semanal e similar no intervalo quinzenal e sem adubação foliar (Figura 1h). As curvas de $S_{a}$ permitem inferir que ocorreu aumento na expansão foliar juntamente à redução da sua espessura quando plantas de fisalis foram submetidas à adubação foliar semanal, sendo o a máxima $\mathrm{S}_{\mathrm{a}}$ atingida ao 14 DAT com tendência ao decréscimo ate os 28 DAT e posterior estabilização.

A partição de matéria seca entre os diferentes órgãos de plantas de fisalis também foi analisada e obtida com elevados coeficientes de determinação, sendo incrementada de forma acentuada a matéria seca de folha e caule a partir dos 14 e 28 DAT, respectivamente $\left(R^{2} \geq 0,94\right)$ (Figura 2$)$.

A matéria seca de folhas $\left(\mathrm{W}_{\mathrm{f}}\right)$, indiferentemente a ao intervalo de adubação, foi similar ao longo do crescimento e aumentou até 126 DAT onde plantas sem adubação atingiram 206,08 $\mathrm{g} \mathrm{m}^{-2}$ e plantas submetidas à adubação semanal e quinzenal obtiveram 199,18 $\mathrm{g} \mathrm{m}^{-2}$ e 216,53 $\mathrm{g} \mathrm{m}^{-2}$, respectivamente (Figura 2a). Inicialmente, as folhas se constituem em dreno metabólico preferencial e a maior alocação de matéria seca em folhas é comum devido ao maior investimento da planta nestes órgãos objetivando o aumento da área foliar útil para a formação de assimilados, enquanto, a estabilização da alocação de matéria seca foliar poderia ser esperada devido à mudança do dreno preferencial para os demais órgãos da planta (LOPES; MAESTRI, 1973).

A matéria seca de caule $\left(\mathrm{W}_{\mathrm{c}}\right)$ aumentou de maneira acentuada até 98 DAT em plantas sob adubação foliar semanal e sem adubação foliar (Figura 2b). Enquanto, plantas sob adubação foliar quinzenal continuaram acumulando matéria seca no caule até 126 DAT, o que indica maior contribuição deste órgão na composição da matéria seca total neste intervalo de adubação comparativamente aos demais, podendo a maior $\mathrm{W}_{\mathrm{c}}$ ter contribuído para uma semelhante produção de matéria seca de frutos de plantas submetidas ao intervalo de adubação semanal. Desse modo, a maior eficiência de conversão de assimilados em matéria seca de caule ocorreu em plantas submetidas à aplicação quinzenal $\left(340,85 \mathrm{~g} \mathrm{~m}^{-2}\right)$ seguida por àquelas sob semanal $\left(198,71 \mathrm{~g} \mathrm{~m}^{-2}\right)$ e sem adubação foliar $\left(197,11 \mathrm{~g} \mathrm{~m}^{-2}\right)$, que foram similares. É evidenciado em plantas sem adubação foliar e adubação semanal que a $\mathrm{W}_{\mathrm{c}}$ atingiu o máximo com posterior tendência a estabilização no período de intensificação da produção de matéria seca de fruto (Figura 2c) que ocorreu aos 84 DAT, indicando os frutos como dreno forte, definitivo e com alta capacidade mobilizadora de assimilados que proporcionam a redução na proporção de matéria seca alocada para as folhas e para o caule (LOPES; MAESTRI, 1973). 
Figura 2. Matéria seca (a, b, c), taxas de produção de matéria seca de folha (d), de caule (e) e de fruto (f) e número de frutos por planta $(\mathrm{g})$ de plantas de fisalis submetidas a três intervalos de adubação foliar. Sendo: 0 dias (—), 7 $\operatorname{dias}(\cdots \cdots)$ e $15 \operatorname{dias}(\cdots \cdots)$.

(a)

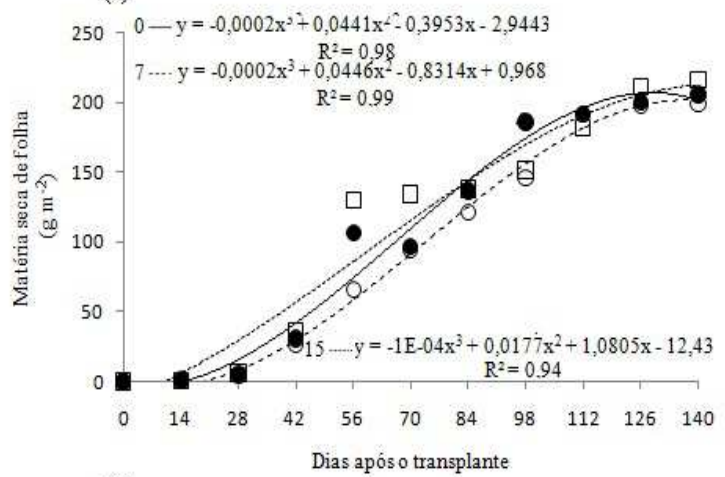

(c)

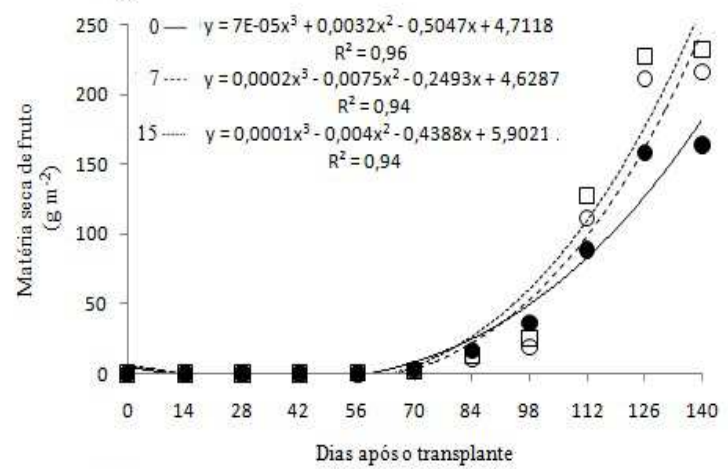

(e)

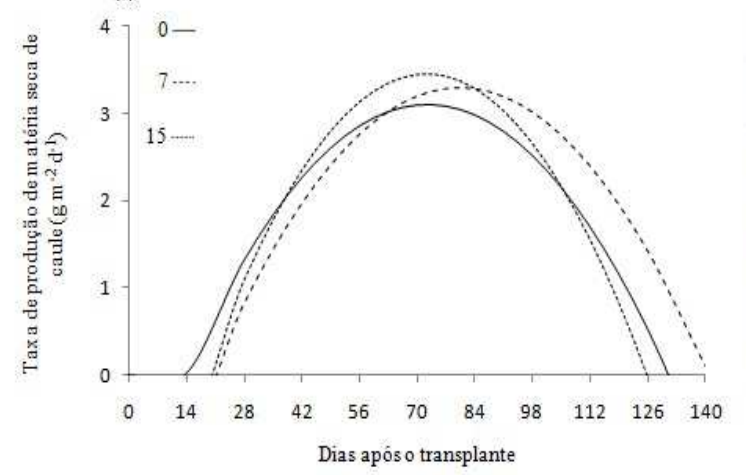

(b)

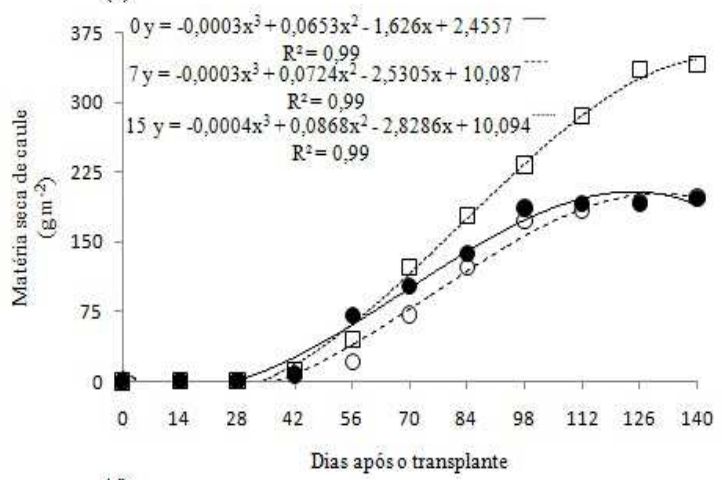

(d)

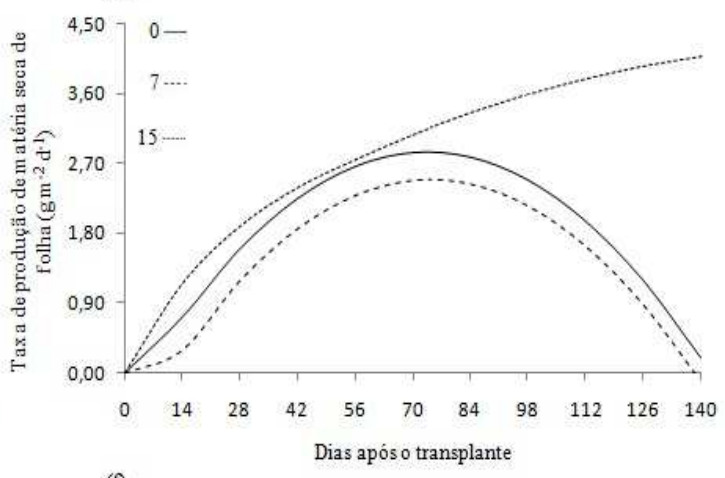

(f)

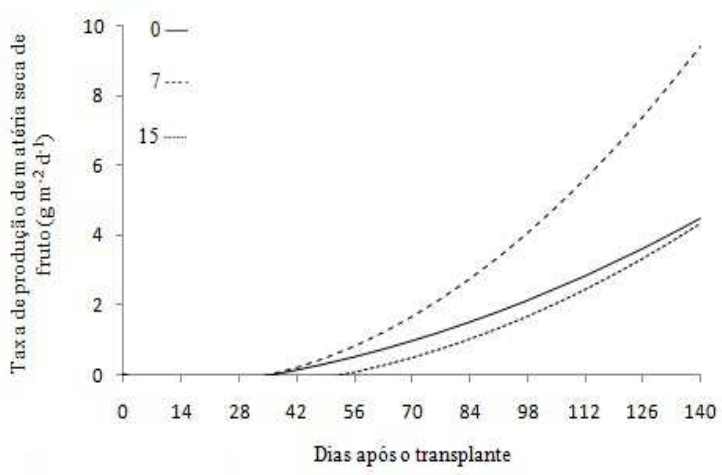

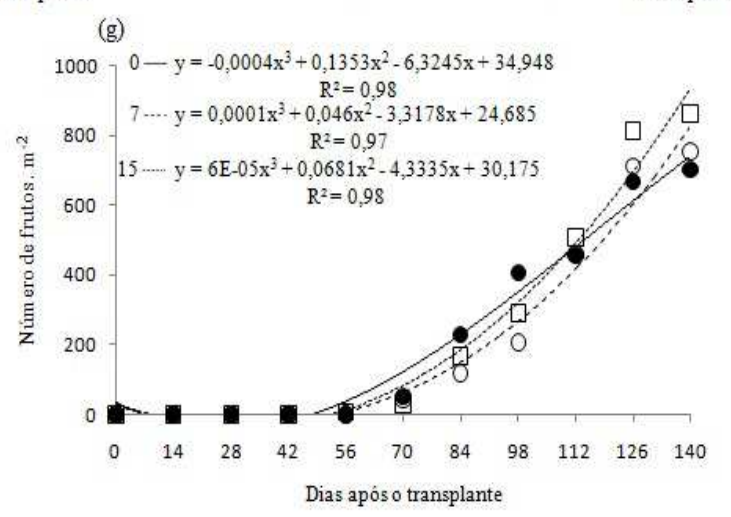

Fonte: Elaboração dos autores. 
Houve tendência ao aumento em $\mathrm{W}_{\mathrm{fr}}$ ao longo do ciclo de cultivo em todos os tratamentos utilizados. Todavia, as maiores $\mathrm{W}_{\mathrm{fr}}$ foram atingidas ao final do ciclo de cultivo e plantas sem adubação foliar atingiram $\mathrm{W}_{\mathrm{fr}}$ menores nesta fase final do desenvolvimento $\left(163,83 \mathrm{~g} \mathrm{~m}^{-2}\right)$ comparativamente as plantas submetidas à adubação foliar semanal (216,26 $\left.\mathrm{g} \mathrm{m}^{-2}\right)$ e quinzenal $\left(232,61 \mathrm{~g} \mathrm{~m}^{-2}\right)$ que foram superiores e semelhantes entre si. Além disso, houve aumento no número de frutos ao longo do desenvolvimento das plantas de fisalis favorecendo o aumento de $\mathrm{W}_{\mathrm{fr}}$,em maior intensidade em plantas submetidas à adubação foliar semanal com 755 frutos $\mathrm{m}^{-2}$ e quinzenal com 862 frutos $\mathrm{m}^{-2}$ que foram comparativamente superiores às plantas sem adubação foliar com 704 frutos $\mathrm{m}^{-2}$ (Figura 2g).

As taxas de produção de matéria seca de folha $\left(\mathrm{C}_{\mathrm{f}}\right)$ foram crescentes até os 70 DAT em plantas sem aplicação de adubação e naquelas sob adubação semanal, enquanto, em plantas sob aplicação quinzenal a taxa de produção de matéria seca de folha foi crescente até os 140 DAT (Figura 2d). A antecipação da estabilização nas taxas de produção de matéria seca de folhas em plantas sem adubação foliar, comparativamente a crescente $\mathrm{C}_{\mathrm{f}}$ em plantas sob adução quinzenal ate os 140 DAT é explicado, em parte pela melhoria da manutenção estrutural foliar ocasionada pela aplicação foliar de nutrientes e proporcionada por tal intervalo de adubação. As taxas de produção de matéria seca de caule $\left(\mathrm{C}_{\mathrm{c}}\right)$ foram incrementadas de maneira acentuada a partir dos 14 DAT em plantas sem adubação foliar e dos 21 DAT naquelas sob adubação semanal e quinzenal (Figura 2e). Plantas submetidas à adubação foliar quinzenal atingiram as $\mathrm{C}_{\mathrm{c}}$ máximas 14 DAT antes das plantas sob aplicação semanal com $\mathrm{C}_{\mathrm{c}}$ superior em comparação a plantas sem aplicação de adubação foliar, porém, inferior a plantas submetidas à adubação foliar quinzenal. Assim, a adubação foliar influenciou de maneira temporal quantitativa positiva nas taxas de produção de matéria seca de caule e de forma mais marcante sobre o maior intervalo de adubação foliar. Quanto à taxa de crescimento de fruto $\left(\mathrm{C}_{\mathrm{fr}}\right)$, foi crescente desde o surgimento dos frutos até o final do desenvolvimento das plantas seguindo a tendência logística esperada, sendo maior em plantas sob adubação foliar semanal, comparativamente, aos demais intervalos de adubação que foram similares entre si.

A partir da análise conjunta e comparativa dos dados de crescimento e partição de assimilados é possível verificar que plantas de fisalis submetidas à adubação foliar quinzenal atingiram maior $\mathrm{W}_{\mathrm{t}}$, $\mathrm{C}_{t}$ e superior número de frutos em comparação aos demais intervalos de adubação. Além disso, apresentaram semelhante $\mathrm{W}_{\mathrm{fr}}$ em relação à plantas submetidas a adubação foliar semanal e superior $\mathrm{W}_{\mathrm{fr}}$ em relação a plantas sem adubação foliar. Desse modo, é possível inferir que a adubação foliar proporcionou benefícios no crescimento e na partição de assimilados em plantas de Physalis peruviana, não havendo diferenças produtivas comparativamente entre o intervalo de adubação semanal e quinzenal.

\section{Referências}

ARANGO, Z. T. M.; RODRÍGUEZ, M. C.; CAMPUZANO, O. I. M. Frutos de Uchuva (Physalis peruviana L.) ecotipo 'Colombia' mínimamente procesados, adicionados con microorganismos probióticos utilizando la ingeniería de matrices. Revista Facultad Nacional de Agronomía, Medellín, v. 63, n. 1, p. 5395-5407, 2010.

AUMONDE, T. Z.; LOPES, N. F.; MORAES, D. M.; PEIL, R. M. N.; PEDÓ, T. Análise de crescimento do híbrido de mini melancia Smile ${ }^{\circledR}$ enxertada e não enxertada. Interciencia, Caracas, v. 36, n. 9, p. 677-681, 2011.

BARREIRO, A. P.; ZUCARELI, A.; ONO, E. O.; RODRIGUES, J. D. Análise de crescimento de plantas de manjericão tratadas com reguladores vegetais. Bragantia, Campinas, v. 65, n. 4, p. 563-567, 2006.

BEVILAQUA, G. A. P.; SILVA FILHO, P. M.; POSSENTI, J. C. Aplicação foliar de cálcio e boro e componentes de rendimento e qualidade de sementes de soja. Ciência Rural, Santa Maria, v. 32, n. 1, p. 31-34, 2002. 
DIAS, L. A. S.; BARROS, W. S. Biometria experimental. Viçosa: Suprema Gráfica e Editora Ltda, 2009. 408 p.

LOPES, N. F.; MAESTRI, M. Análise de crescimento e conversão de energia solar em milho (Zea mays L.) em Viçosa, Minas Gerais. Revista Ceres, Viçosa, v. 20, n. 109, p. 189-201, 1973.

MARENCO, R. A.; LOPES, N. F. Fisiologia vegetal: fotossíntese, respiração, relações hídricas e nutrição mineral. 3. ed. Viçosa: UFV, 2009. 468 p.

RADFORD, P. J. Growth analysis formulae: their use and abuse. Crop Science, Berkshire, v. 7, n. 3, p. 171175, 1967.

RICHARDS, F. J. The quantitative analysis of growth. In: STEWWARD, F. C. (Ed.). Plant physiology. New York: Academic press, 1969. p. 3-76.

RODRIGUES, D. S.; PONTES, A. L.; MINAMI, K.; DIAS, C. T. S. Quantidade absorvida e concentrações de micronutrientes em tomateiro sob cultivo protegido. Scientia Agricola, Piracicaba, v. 59, n. 1, p. 137-144, 2002.
SEVERO, J.; LIMA, C. S. M.; COELHO, M. T.; RUFATTO, A. R.; ROMBALDI, C. V.; SILVA, J. A. Atividade antioxidante e fitoquímicos em frutos de physalis (Physalis peruviana, L.) durante o amadurecimento e o armazenamento. Revista Brasileira de Agrociência, Pelotas, v. 16, n. 1-4, p. 77-82, 2010.

THOMÉ, M.; OSAKI, F. Adubação de nitrogênio, fósforo e potássio no rendimento de Physalis spp. Revista Acadêmica: Ciências Agrárias e Ambientais, Curitiba, v. 8, n. 1, p. 11-18, 2010.

URCHEI, M. A.; RODRIGUES, J. D.; STONE, L. F. Análise de crescimento de duas cultivares de feijoeiro sob irrigação, em plantio direto e preparo convencional. Pesquisa Agropecuária Brasileira, Brasília, v. 35, n. 3, p. 497-506, 2000.

WU, S. J.; NG, L. T.; HUANG, Y. M.; LIN, D. L.; WANG, S. S.; HUANG, S. N.; LIN, C. C. Antioxidant activities of Physalis peruviana. Biological \& Pharmaceutical Bulletin, Tokyo, v. 28, n. 6, p. 963-966, 2005. 